\title{
Intratumoral cycling hypoxia inhibits expression level of estrogen receptor to promote the formation of heterogeneous sub-clones in luminal A breast cancer
}

\section{Bing Song}

Shengjing Hospital of China Medical University

\section{Gaofeng Zhang}

Cardiff University

Jianyi Li ( $\sim$ sjbreast@yeah.net )

Shengjing Hospital of China Medical University https://orcid.org/0000-0002-0556-9111

\section{Ye Kang}

Shengjing Hospital of China Medical University

\section{Linna Kong}

Jinan Central Hospital Affiliated to Shandong University

\section{Yan Ma}

Shengjing Hospital of China Medical University

Hong Shu

Shengjing Hospital of China Medical University

\section{Yang Zhang}

Shengjing Hospital of China Medical University

\section{Shi Jia}

Shengjing Hospital of China Medical University

\section{Zhenrong Wang}

Shengjing Hospital of China Medical University

\section{Research article}

Keywords: Luminal A breast cancer, cycling hypoxia, estrogen receptor, heterogeneous sub-clones

Posted Date: March 3rd, 2020

DOI: https://doi.org/10.21203/rs.3.rs-15909/v1

License: @ (i) This work is licensed under a Creative Commons Attribution 4.0 International License. Read Full License 


\section{Abstract}

Background

The expression level of estrogen receptor (ER) is positively correlated with chemoresistance in patients with Luminal A tumor (LAT). ER expression level alters frequently after neoadjuvant chemotherapy which may be related with hypoxia. The spatial and temporal heterogeneity of tumor sub-clones is one of the major contributors to treatment failure. It is essential to investigate how the intratumoral heterogeneous sub-clones survive hypoxic microenvironment in LAT.

\section{Material and Methods}

LAT with largest cross section was divided into micro-sections, the expressions of hypoxia inducible factor-1 (HIF-1) and ER were then detected by immunohistochemistry. The intratumoral distribution of micro-vessels was assessed by 3D reconstruction and stained CD34; the cycling hypoxia model of MCF-7 was established in a step fashion to investigate the changes in HIF-1 and ER expressions. All statistical analyses were performed using SPSS software (version 17.0 for Windows).

Results

There was a negative correlation between the expressions of ER-alpha and HIF-1alpha $(c=-2.40 ; p=0.044)$ as assessed by mean optical density values in the maximal cross section of tumor. As shown by 3D ultrasound image, the center of tumor had less functional micro-vessels compared with the periphery $(P<0.05)$. From the periphery to the center of tumors in the large sections from 8 patients with LAT, the expressions of ER, progesterone receptor and CD34 were gradually decreased with HIF-1alpha expression showing an opposite direction. There was a negative correlation between expressions of ER-alpha and HIF-1alpha, and between expressions of CD34 and HIF-1alpha. No significant difference was noted in the outcomes of cytometry between the hypoxia and control groups. ER-alpha expression gradually decreased with the time course of cycling hypoxia with HIF-1alpha showing an opposite direction.

\section{Conclusion}

LAT is composed of heterogeneous sub-clone cells which can be distinguished by ER-alpha and HIF-1alpha. The distribution of heterogeneous sub-clone cells was closely related with heterogeneous microenvironment of hypoxia / reoxygenation.

Keywords: Luminal A breast cancer, cycling hypoxia, estrogen receptor, heterogeneous sub-clones.

\section{Background}

The rate of pathological complete response (pCR) in patients with luminal A tumor (LAT) is far lower than that in those with triple negative breast cancer or human epidermal growth factor receptor 2 (HER2)-enriched tumors, as generally acknowledged by physicians involved in neoadjuvant chemotherapy (NAC). ${ }^{[1]}$ The expression level of estrogen receptor (ER) is positively correlated with the resistance to NAC. ${ }^{[2]}$ Meanwhile, the level of ER expression alters frequently post neoadjuvant chemotherapy. ${ }^{[3]}$ It has been found that MCF-7 breast cancer cells were resistant to doxorubicin, which was associated with activation of hypoxia inducible factor-1 (HIF-1). ${ }^{[4]}$ As demonstrated in a recent study, hypoxia inhibited ER expression in ER-positive breast cancer cells, the molecular mechanism, however, remained unclear. ${ }^{[5]}$ In a clinical context, although difference exists, the agreement rates between core needle biopsy (CNB) and surgical specimens in immunohistochemically detecting the expressions of ER, progesterone receptor (PR) and HER2 were as 
high as $81.3 \%, 92.9 \%$ and $89.3 \%$, respectively. ${ }^{[6]}$ A review of 45 studies on expressions in lymph node metastasis, distant metastasis and local recurrence revealed that the average phenotypic drift in ER, PR, and Her-2 expression was from $6.6-32.0 \% .{ }^{[7]}$ The resulting spatial and temporal heterogeneity becomes the major contributor to treatment failure, and poses a huge challenge to comprehensively understand the characteristics of the tumor. [8]

If the intratumoral heterogeneity occurs from the tumorigenesis, the extratumoral heterogeneity could be easily understood. Thus, it is essential to investigate how the LAT intratumoral heterogeneous sub-clones survive under hypoxia. Besides, the intratumoral heterogeneous hypoxic zones are believed to evolve dynamically. The model of hypoxia / reoxygenation, termed as "cycling hypoxia", is a well-recognized phenomenon in animal and human solid tumors. ${ }^{[9]}$ Therefore, the aim of the present study was to investigate intratumoral heterogeneity by assessing expressions of HIF-1 and ER sub-clones under intratumoral cycling hypoxia in LAT. HIF-1 and ER expressions were detected using immunohistochemical technique from micro-blocks and large sections; the intratumoral distribution of micro-vessels was observed and assessed using 3D reconstruction and stained CD34; and the ladder-type cycling hypoxia model of MCF-7 was established.

\section{Methods}

\subsection{The expression maps of ER-alpha and HIF-1alhpa in tumor tissue of micro-blocks}

On 12 August 2015, a piece of tumor tissue with a maximal cross-sectional area was obtained paralleled to the pectoralis major in an open surgery from a patient who was diagnosed with LAT via preoperative biopsy. The patient was labeled as "Patient One" (Table 1). The thickness of the "pancake" like tissue was approximately $3 \mathrm{~mm}$. Fat tissue was manually removed before the sample was divided into micro-blocks of less than $3 \mathrm{~mm} \times 3 \mathrm{~mm} \times 3 \mathrm{~mm}$ and numbered according to the cross-sectional shape of tumor (Fig. <link rid="fig1" $>1</$ link $>, A-1$ to A-3). Each micro-block was detected by immunohistochemistry (IHC) for ER-alpha (1:200 dilution; ZETA, Bosterbio, USA) and HIF-1alpha (ab82832\#, ABCAM, UK), respectively, in the Department of Histology and Pathology of the hospital. The details of surgical protocols were published elsewhere. ${ }^{[10]}$ Integrated Optical Density (IOD) was calculated as the sum of grey values for each pixel in the detected area, divided by the total area covered by breast cancer cells. ${ }^{[11]}$ The expressions of ER-alpha and HIF-1alpha were represented as the Mean Optical Density (MOD) of each micro-block which obtained from more than five independent views. 
Table 1

Patient characteristics

\begin{tabular}{|c|c|c|c|c|c|c|c|c|c|}
\hline Characteristics & Patient 1 & $\begin{array}{l}\text { Patient } \\
2\end{array}$ & $\begin{array}{l}\text { Patient } \\
3\end{array}$ & $\begin{array}{l}\text { Patient } \\
4\end{array}$ & $\begin{array}{l}\text { Patient } \\
5\end{array}$ & $\begin{array}{l}\text { Patient } \\
6\end{array}$ & $\begin{array}{l}\text { Patient } \\
7\end{array}$ & $\begin{array}{l}\text { Patient } \\
8\end{array}$ & $\begin{array}{l}\text { Patient } \\
9\end{array}$ \\
\hline Age(yrs) & 43 & 52 & 39 & 48 & 42 & 57 & 56 & 40 & 46 \\
\hline \multicolumn{10}{|l|}{ Menopause } \\
\hline Postmenopausal & & $\bullet$ & & & & • & $\bullet$ & & \\
\hline Premenopausal & - & & - & 0 & $\bullet$ & & & $\bullet$ & 0 \\
\hline \multicolumn{10}{|l|}{ Family History } \\
\hline No & - & - & & 0 & $\bullet$ & $\bullet$ & $\bullet$ & $\bullet$ & $\bullet$ \\
\hline Yes & & & $\bullet$ & & & & & & \\
\hline \multicolumn{10}{|l|}{ Quadrant } \\
\hline Areolar & & & & & $\bullet$ & & & & \\
\hline \multicolumn{10}{|l|}{ Inner upper } \\
\hline \multicolumn{10}{|l|}{ Inner lower } \\
\hline Outer lower & & $\bullet$ & & & & & $\bullet$ & & \\
\hline Outer upper & - & & - & $\bullet$ & & ○ & & $\bullet$ & $\bullet$ \\
\hline Diameter $(\mathrm{cm})$ & 2.5 & 2.8 & 2.3 & 3.0 & 2.5 & 3.4 & 2.5 & 2.7 & 3.8 \\
\hline \multicolumn{10}{|l|}{$\begin{array}{l}\text { Histological } \\
\text { Grade }\end{array}$} \\
\hline \multicolumn{10}{|l|}{ । } \\
\hline II & - & & & & ○ & & & & - \\
\hline III & & $\bullet$ & $\bullet$ & $\bullet$ & & $\bullet$ & $\bullet$ & $\bullet$ & \\
\hline \multicolumn{10}{|l|}{$\begin{array}{l}\text { Cancer } \\
\text { Thrombosis }\end{array}$} \\
\hline Negative & & - & & & $\bullet$ & & $\bullet$ & $\bullet$ & ○ \\
\hline Positive & $\bullet$ & & 0 & $\bullet$ & & $\bullet$ & & & \\
\hline \multicolumn{10}{|l|}{$\begin{array}{l}\text { Nodal } \\
\text { Metastasis }\end{array}$} \\
\hline Negative & & $\bullet$ & $\bullet$ & & $\bullet$ & $\bullet$ & $\bullet$ & $\bullet$ & \\
\hline Positive & $\bullet$ & & & $\bullet$ & & & & & $\bullet$ \\
\hline $\mathrm{ER}(\%)$ & 80 & 60 & 80 & 90 & 90 & 80 & 70 & 90 & 60 \\
\hline $\mathrm{PR}(\%)$ & 70 & 50 & 80 & 90 & 80 & 70 & 70 & 90 & 50 \\
\hline Ki67(\%) & 15 & 10 & 10 & 15 & 10 & 7 & 10 & 3 & 15 \\
\hline
\end{tabular}




\begin{tabular}{|c|c|c|c|c|c|c|c|c|c|}
\hline Characteristics & Patient 1 & $\begin{array}{l}\text { Patient } \\
2\end{array}$ & $\begin{array}{l}\text { Patient } \\
3\end{array}$ & $\begin{array}{l}\text { Patient } \\
4\end{array}$ & $\begin{array}{l}\text { Patient } \\
5\end{array}$ & $\begin{array}{l}\text { Patient } \\
6\end{array}$ & $\begin{array}{l}\text { Patient } \\
7\end{array}$ & $\begin{array}{l}\text { Patient } \\
8\end{array}$ & $\begin{array}{l}\text { Patient } \\
9\end{array}$ \\
\hline Mastectomy & - & - & & & - & - & - & & 0 \\
\hline Tumorectomy & & & $\bullet$ & • & & & & $\bullet$ & \\
\hline Study & $\begin{array}{l}\text { Expression } \\
\text { maps }\end{array}$ & Intratum & ral heter & geneity & & & & & \\
\hline
\end{tabular}

\subsection{Intratumoral heterogeneity and oxygen supply (vascularization) study of luminal A breast cancer}

Between 1 February and 30 June 2016, 20 patients treated in the Department of Breast Surgery, Shengjing Hospital of China Medical University, Shenyang, China were investigated. The study was approved by the Ethics Committee of Shengjing Hospital of China Medical University. The study consisted of two sections. Inclusion criteria of the first section were: 1) no previous history of breast cancer or other malignancies; 2) not pregnant at the time of diagnosis; 3) no history of NAC; 4) BI-RADs $4 \mathrm{C}$ or 5 as determined by the preoperative comprehensive imaging assessment (mammography and ultrasound); ${ }^{[12]}$ and 5) the longest diameter of the tumor $>2 \mathrm{~cm}$.

Conventional ultrasound and 3D vascular images were obtained using the Philips IU22 system with a linear 3D transducer. QLAB vascular analysis (Philips) was used to calculate the volume of tumor and quantitative vascularization index $(\mathrm{VI})$. Small spheres of varying sizes were drawn in the center of the tumor (Fig. 2, A-1 to A-3). All tumors underwent intraoperative instant frozen histopathology to confirm malignancy.

The inclusion criteria for the second section were: 1) invasive ductal carcinoma; 2) ER $\geq 50 \%$; 3) Ki67 < 20\%; and 4) HER2 negative. Tumors from eight patients met the above criteria thus were completely embedded and made into large sections. ${ }^{[13]}$ The characteristics of these patients are listed as Patient 2 to 9 in Table 1. The expressions of ER, PR (1:200 dilution; ZETA, Bosterbio, USA), CD34 (1:500 dilution; ZM-0046, Zhongshanjinqiao, China) and HIF-1alpha (ab82832\#, ABCAM, UK) were assessed via immunohistochemically staining. Through the view fields of the microscope, the tumors were arranged from the edge to the center based on the boundary of the tumor, and were rotationally divided into non-overlapping zones (Fig. 2, C-1 to C-13). The expression levels of these markers in each zone were analyzed to assess the intratumoral heterogeneity.

\subsection{Ladder-type cycling hypoxia and cytometry}

MCF-7 cells (provided by Professor Bing, originally obtained from the ATCC (HTB-22, Rockville, MD, USA), the passage number $<6$ and the mycoplasma screening was safe) were routinely maintained in Dulbecco's modified Eagle's medium/Ham's F12 (Sigma-Aldrich, Irvine, UK) supplemented with 10\% fetal bovine serum (FBS) and $1 \times$ penicillin and streptomycin. Cells were randomly allocated into two groups: cycling hypoxia group and control group (normoxic environment). Four cycles of hypoxic culture $\left(1-2 \% \mathrm{O}_{2}, 5 \% \mathrm{CO}_{2}\right.$, and $93-94 \% \mathrm{~N}_{2}$ ) were performed for $24,36,48$, and $72 \mathrm{~h}$ respectively in a hypoxic workstation (YQX-15 II, Shanghai Qiaofeng Corp, China), followed by normoxic culture $\left(21 \% \mathrm{O}_{2}, 5 \% \mathrm{CO}_{2}\right.$, and $\left.74 \% \mathrm{~N}_{2}\right)$ for $24 \mathrm{~h}$ to induce the MCF-7CH. Cell passaging was initiated after hypoxic cycle in MCF$7 \mathrm{CH}$ group. Cytometry for cell passaging in the control group underwent at the same time point (i.e. 84,156 and $276 \mathrm{~h}$, respectively after the test started) with the hypoxia group (Fig. 3).

\subsection{Heterogeneous sub-clones in vitro were induced by cycling hypoxia}


The expressions of HIF-1alpha and ER-alpha were examined by Western Blot $(n=3)$. The resulting blots were probed with rabbit monoclonal (\#EPR4097, Estrogen Receptor alpha, Abcam, UK), rabbit polyclonal (\#ab82832, Anti-HIF-1 alpha, Abcam, UK), and secondary antibodies (\#ab6940, Goat polyclonal Secondary Antibody to Rabbit IgG; H\&L, Abcam, UK), respectively (Fig. 4, A-1 \& A-2). The expressions of ER-alpha (1:200 dilution; ZETA, Bosterbio, USA) for MCF-7CH and MCF-7 were also examined by immunofluorescence assay for three times. Fluorescent gathered in the nucleus of ER positive cells. Photos were taken for more than 100 cells before analyzed by ImageJ (Fig. 4, B-1 \& B-2).

\subsection{Statistical analysis}

All the cell experiments were performed three times. P value $<0.05$ was considered to be statistically significant. All statistical analyses were performed using SPSS software (version 17.0 for Windows). Pearson correlation test was used to investigate the relationship of expressions between the markers.

\section{Result}

\subsection{The Expression map of ER-alpha and HIF-1alhpa in LAT}

ER and HIF-1alpha expressions of each micro tissue block were assessed by ImageJ for an MOD value, and were endowed with a blue and red color, respectively. The greater the MOD value, the darker the blue or red color was endowed. The expression map of ER-alpha (MOD) on the maximal cross section of the tumor was presented in Fig. <link rid="fig1">1</link>, B-1. ER staining for tissue block \#40 and \#9 was shown in Fig. 1, B-2 and B-3. The expression map of HIF-1alpha (MOD) of the tumor with the maximal cross section was presented in Fig. <link rid="fig1">1</link>, C-1. HIF-1 alpha staining for tissue block \#21 and \#51 were shown in Fig. 1, C-2 and C-3. There was a significantly negative correlation ( $c=-2.40 ; p=0.044$ ) between the expressions of ER-alpha and HIF-1alpha of the tumor with the maximal cross section, as shown in Fig. <link rid="fig1" >1</link>, D-1\& D-2.

\subsection{Intratumoral heterogeneity and oxygen supply study for Luminal A breast cancer}

The intratumoral microvascular distribution in one patient with LAT was investigated using the 3D ultrasonic imaging. The tumor volume was $5.1 \mathrm{ml}$ with a microvascular density (MD) of 1.5\% (Fig. 2, A-1). If a small virtual sphere was built at the tumor center, the tumor volume and MD were $0.53 \mathrm{ml}$ and $0.3 \%$, respectively (Fig. $<$ link rid="fig3" $>2</$ link>, A-2). If a large homocentric virtual sphere was built, the volume and MD were $0.9 \mathrm{ml}$ and $1.0 \%$, respectively (Fig. 2A-3). The mean MDs of the tumors from eight patients who met the criteria were presented in Fig. $2 \mathrm{~B}$. The volumes of tumors ranged from 4.0 to $8.0 \mathrm{ml}$, whereas the volumes of the large and small virtual spheres ranged from 0.8 to $2.0 \mathrm{ml}$ and 0.2 to $0.7 \mathrm{ml}$, respectively. The difference was statistically significant $(p<0.001)$.

The pathological report for Patient \#4 showed that the expressions of ER, PR, and Ki67 were 90\%, 90\% and 15\%, respectively, and the Her2 expression was negative by the routine IHC (Fig. 2, C-1). Part of the tumor tissue was used for big pathological section to investigate intratumoral heterogeneity of ER, PR, CD34 and HIF-1alpha expressions. Zone \#3, \#21 and \#24 represent the edge, medium and center of tumor, respectively (Fig. <link rid="fig3" >2</link>, C-2 to C13). There was a negative correlation between the expressions of ER and HIF-1alpha $(c=-0.433, p=0.027)($ Fig. 2, C-14) and a negative correlation between the expressions of CD34 and HIF-1alpha ( $c=-0.621, p=0.001)$ (Fig. 2, C-15). From the edge to the center of the tumor, the expressions of ER, PR and CD34 were gradually reduced in all patients (Fig. 2, D1 to D-3), whereas the expression of HIF-1alpha was increased (Fig. 2D-4).

\subsection{Heterogeneous sub-clones in vitro in relation to cycling hypoxia}


No significant difference was noted in the outcomes of cytometry between the hypoxia and control groups, as assessed at the some checking points for the two groups (Fig. 3). With the increasing cycles of cycling hypoxia, the expression of HIF-1alpha by Western Blot was increased, whereas the expression of ER-alpha was decreased (Fig. 4, A$1 \& A-2)$. The fluorescence intensity of ER-alpha by immunofluorescence assay was decreased after 4 cycles of cycling hypoxia treatment $(p<0.001)$ (Fig. 4, B-1\& B-2).

\section{Discussion}

By studying micro-block tumor tissues, we have found that the expressions of ER-alpha and HIF-1alhpa were heterogeneous (Fig. 1). ER is the most important marker to predict prognosis, guide treatment for patients with breast cancer, and the HIFs master the transcriptional response to local tissue hypoxia, a hallmark of solid tumors. ${ }^{[14,15]}$ Previous studies revealed that hypoxia could inhibit ER expression in ER-positive breast cancer cells. ${ }^{[16]}$ We also demonstrated a negative correlation between the expressions of ER-alpha and HIF-1alpha (Fig. 1 and Fig. 2). It was well established that the energy consumption differs within the tumor tissue with predominance of glycolysis in the zone of central necrosis and phosphorylation in surrounding microenvironment. ${ }^{[17]}$ This phenomenon is closely related to the heterogeneous distribution of micro-vessels. ${ }^{[18]}$ As shown by the 3D ultrasound images, the center of tumor was free of functional micro-vessels (Fig. 2). Generally, most human tumors are heterogeneous, consisting of cellular clones of different natures, which present different characteristics at varying frequencies. ${ }^{[19]}$ In recent years, growing number of studies have used large sections to investigate intratumoral heterogeneity. ${ }^{[20,21]}$ From the edge to the center of the tumor, the gradually decreased expressions in ER, PR and CD34 were shown on the large sections with the expression of HIF-1alpha showing an opposite trend (Fig. 2). The expression of CD34 and HIF-1alpha was negatively correlated (Fig. 2). As an important marker of vascular endothelial cell, CD34 can, to some extent, represent microvessel density. [22] In addition, the distribution of intratumoral microvessels is a potential prognostic indicator for patients with breast cancer. ${ }^{[23]}$ Our findings suggested that LAT tissues were composed of cell population with different sub-clones which can be distinguished by the expression levels of ER-alpha and HIF-1alpha. In 1955, Thomlinson and Gray first explained tumor hypoxia. They proposed the concept of gradually decreasing oxygen gradient from the periphery to the center of the tumor sphere. They found that cancerous cells grew in the periphery of the vascular stroma, while the central region of larger tumor was necrotic, and was surrounded by intact cells with ring appearance. ${ }^{\text {[24] }}$

In 1992, Semenza and Wang discovered HIF in the extracts of hypoxic hepatocellular carcinoma cell line Hep3B. ${ }^{\text {[25] }}$ HIFs family is responsible for the adaptation of cellular metabolism to hypoxia. ${ }^{[26]}$ Recent evidence revealed that chronic repeated exposure to hypoxia and reoxygenation seems to be beneficial to tumor growth. ${ }^{[27]}$ After the initial trial and error, we established a cycling hypoxia model in a step fashion to induce the MCF-7 phenotypic drift, and the hypoxia/reoxygenation ratio was adjusted from 1:1 to 1:3. The step-type cycling hypoxia potentially protected the cell survival from long term hypoxia (Fig. 3). Furthermore, the HIF-1alpha expression level was gradually increased with the time course of cycling hypoxia, and the ER expression trended in an opposite direction (Fig. 4). In fact, different phenotypic cells with varying expression levels of ER-alpha and HIF-1alpha could be obtained artificially by adjusting oxygen supply. These in vitro cultured cells were similar to the large section cells obtained from patients. Therefore, it seems reasonable to hypothesize that the intratumoral heterogeneous oxygen supply induces the production of heterogeneous sub-clone cells which are adapted to the hypoxia / reoxygenation microenvironment. If the hypothesis is true, that is, tumors are composed of dynamitic sub-clones from the scratch under the pressure of hypoxia, which definitely will help to comprehend its spatial and temporal heterogeneity.

Oxygen is vital for the most living organisms. William G. Kaelin and Gregg L. Semenza of the United States and Sir Peter J. Ratcliffe of the United Kingdom, the winners of the 2019 Nobel Prize in Physiology or Medicine, discovered 
pathways through which cells perceive and adapt to oxygen. ${ }^{[28]}$ Tumor as a "society" composed of heterogeneous subclones induced by heterogeneous oxygen supply, is well prepared for future changes in the hypoxia / reoxygenation microenvironment. For example, cancer composed of predominant sub-clones at the periphery and non-predominant sub-clones at the center of tumor; at least one sub-clone becomes a new dominant clone by adapting to changes in the tumor microenvironment caused by the therapeutic stress, such as chemotherapy or radiotherapy. In previous preclinical and clinical studies, positive ER expression in breast cancer cells was associated with decreased sensitivity

to chemotherapy. ${ }^{[29,30]}$ We speculate that LAT could adapt to chemotherapy by reducing the expression level of ER. Surely, huge complicated work is yet to be done, e.g. how to convert the chemotherapy or radiotherapy stress to hypoxia; how the HIFs family inhibits the ER; and why the cells loss the ER phenotype and gain an aggressive phenotype.

\section{Conclusions}

In summary, we used micro-block, large section and Doppler imaging technique and preliminarily conformed that LAT is composed of multiple heterogeneous sub-clones which can be distinguished by HIF-1 and ER. This study simulated the formation process of heterogeneous sub-clones in vitro under cycling hypoxia, suggesting different heterogeneous subclones are adapted to their hypoxia / reoxygenation microenvironment.

\section{Abbreviations}

NAC

neoadjuvant chemotherapy

pCR

pathological complete response

LAT

luminal A tumor

HER2

human epidermal growth factor receptor 2

ER

estrogen receptor

HIF-1

hypoxia inducible factor-1

CNB

core needle biopsy

PR

progesterone receptor

$\mathrm{IHC}$

immunohistochemistry

IOD

Integrated Optical Density

MOD

Mean Optical Density

$\mathrm{VI}$

vascularization index

FCS

fetal calf serum 
MD

microvascular density

\section{Declarations}

\section{Ethics approval and consent to participate}

The study was approved by the Ethics Committee of Shengjing Hospital of China Medical University.

\section{Consent for publication}

All presentations have consent for publication.

\section{Availability of data and material}

The datasets used and analyzed during the current study are available from the corresponding author on reasonable request.

\section{Competing interests}

All authors declare no conflict of interests.

\section{Funding}

The funding for this study was provided by the National Natural Science Foundation of China, No. 81528010 to JL and BS.

\section{Authors' contributions}

LJY and SB designed the proposal and drafted the manuscript. ZGF, KLN and WZR participated in data collection. KY and SH participated in immumohistochemical stain and analysis. MY carried out the ultrasound analysis. SB, LJY, ZY and JS participated in total data analysis. All authors read and approved the final manuscript.

\section{Acknowledgements}

Not applicable

\section{References}

1. Bonnefoi H, Litière S, Piccart M, etc al, EORTC 10994/BIG 1-00 Study investigators. Pathological complete response after neoadjuvant chemotherapy is an independent predictive factor irrespective of simplified breast cancer intrinsic subtypes: a landmark and two-step approach analyses from the EORTC 10994/BIG 1-00 phase III trial. Annals of oncology: official journal of the European Society for Medical Oncology, 25(6), 1128-1136. doi:10.1093/annonc/mdu118 PMID 24618153.

2. Kim SI, Sohn J, Koo JS, etc al. Molecular subtypes and tumor response to neoadjuvant chemotherapy in patients with locally advanced breast cancer. Oncology. 2010;79(5-6):324-30. doi: 10.1159/000322192. Epub 2011, Mar 23. PMID: 21430399.

3. Wu YT, Li X, Lu LJ, et al. Effect of neoadjuvant chemotherapy on the expression of hormone receptors and Ki-67 in Chinese breast cancer patients: A retrospective study of 525 patients [published online ahead of print, 2017 Nov 1]. J Biomed Res. 2017;32(3):191-197. doi:10.7555/JBR.32.20170059 
4. Doublier, S., Belisario, D. C., Polimeni, M., etc al. HIF-1 activation induces doxorubicin resistance in MCF7 3-D spheroids via P-glycoprotein expression: a potential model of the chemo-resistance of invasive micropapillary carcinoma of the breast. BMC cancer, 12, 4. doi:10.1186/1471-2407-12-4 PMID 22217342.

5. Wolff, M., Kosyna, F. K., Dunst, J., etc al. Impact of hypoxia inducible factors on estrogen receptor expression in breast cancer cells. Archives of biochemistry and biophysics, 613, 23-30. doi:10.1016/j.abb.2016.11.002 PMID 27823907.

6. Tamaki K, Sasano H, Ishida T, etc al. Comparison of core needle biopsy (CNB) and surgical specimens for accurate preoperative evaluation of ER, PgR and HER2 status of breast cancer patients. Cancer science, 101(9), 2074-2079. doi:10.1111/j.1349-7006.2010.01630.x PMID 20557310.

7. Jabbour M. N., Massad, C. Y., \& Boulos, F. I. Variability in hormone and growth factor receptor expression in primary versus recurrent, metastatic, and post-neoadjuvant breast carcinoma. Breast cancer research and treatment, 135(1), 29-37. doi:10.1007/s10549-012-2047-z PMID 22484731.

8. Song, J. L., Chen, C., Yuan, J. P.,etc al. Progress in the clinical detection of heterogeneity in breast cancer. Cancer medicine, 5(12), 3475-3488. doi:10.1002/cam4.943 PMID 27774765.

9. Matsumoto, S., Yasui, H., Mitchell, J. B., etc al. Imaging cycling tumor hypoxia. Cancer research, 70(24), 1001910023. doi:10.1158/0008-5472. CAN-10-2821 PMID 21159626.

10. Badowska-Kozakiewicz A, Sobol M, Patera J. Expression of Hypoxia-Inducible Factor 1a in Invasive Breast Cancer with Metastasis to Lymph Nodes: Correlation with Steroid Receptors, HER2 and EPO-R. Adv Clin Exp Med. 2016;25(4):741-750. doi:10.17219/acem/63143

11. Clemons, M. J., Bibby, M. C., El Teraifi, H., etc al (2002). Heterogeneity of O6-alkylguanine DNA-alkyltransferase expression in human breast tumours. British journal of cancer, 86(11), 1797-1802. doi:10.1038/sj.bjc.6600324 PMID 12087469.

12. Cho KR, Seo BK, Woo OH, et al. Breast Cancer Detection in a Screening Population: Comparison of Digital Mammography, Computer-Aided Detection Applied to Digital Mammography and Breast Ultrasound. J Breast Cancer. 2016;19(3):316-323.

13. Tot T. Clinical relevance of the distribution of the lesions in 500 consecutive breast cancer cases documented in large-format histologic sections. Cancer. 2007;110(11):2551-2560. doi:10.1002/cncr.23052

14. Tang J, Cui Q, Zhang D, etc al. An estrogen receptor (ER)-related signature in predicting prognosis of ER-positive breast cancer following endocrine treatment. J Cell Mol Med. 2019 Aug;23(8):4980-4990. doi:

10.1111/jcmm.14338. Epub 2019 May 23. PMID: 31124293; PMCID: PMC6652714.

15. Bertout JA, Patel SA, Simon MC. The impact of 02 availability on human cancer. Nat Rev Cancer. 2008;8(12):967975. doi:10.1038/nrc2540

16. Wolff M, Kosyna FK, Dunst J, etc al. Impact of hypoxia inducible factors on estrogen receptor expression in breast cancer cells. Arch Biochem Biophys. 2017 Jan 1; 613: 23-30. doi: 10.1016/j.abb.2016.11.002. Epub 2016 Nov 5. PMID: 27823907.

17. Stadlbauer A, Zimmermann M, Doerfler A, etc al. Intratumoral heterogeneity of oxygen metabolism and neovascularization uncovers 2 survival-relevant subgroups of IDH1 wild-type glioblastoma. Neuro Oncol. 2018 Oct 9;20(11):1536-1546. doi: 10.1093/neuonc/noy066. PMID: 29718366; PMCID: PMC6176796.

18. Stadlbauer A, Mouridsen K, Doerfler A, etc al. Recurrence of glioblastoma is associated with elevated microvascular transit time heterogeneity and increased hypoxia. J Cereb Blood Flow Metab. 2018 Mar;38(3):422432. doi: 10.1177/0271678X17694905. Epub 2017 Feb 24. PubMed PMID: 28273720; PubMed Central PMCID: PMC5851132. 
19. Janiszewska M, Tabassum DP, Castaño Z, etc al. Subclonal cooperation drives metastasis by modulating local and systemic immune microenvironments. Nat Cell Biol. 2019, Jul;21(7):879-888. doi: 10.1038/s41556-019-0346x. Epub 2019 Jul 1. PMID: 31263265; PMCID: PMC6609451.

20. Tsourlakis MC, Stender A, Quaas A, etc al. Heterogeneity of ERG expression in prostate cancer: a large section mapping study of entire prostatectomy specimens from 125 patients. BMC Cancer. 2016 Aug 17;16:641. doi: 10.1186/s12885-016-2674-6. PMID: 27530104; PMCID: PMC4988055.

21. Schroeder C, Grell J, Hube-Magg C, etc al. Aberrant expression of the microtubule-associated protein tau is an independent prognostic feature in prostate cancer. BMC Cancer. 2019 Mar 1;19(1):193. doi: 10.1186/s12885-0195390-1. PubMed PMID: 30823906; PubMed Central PMCID: PMC6397474.

22. Bonacho T, Rodrigues F, Liberal J. Immunohistochemistry for diagnosis and prognosis of breast cancer: a review [published online ahead of print, 2019 Sep 10]. Biotech Histochem. 2019;1-21. doi: 10. 1080/ 10520295. 2019. 1651901

23. Li J, Zhang Y, Zhang W, etc al. Contrast enhanced computed tomography is indicative for angiogenesis pattern and display prognostic significance in breast cancer. BMC Cancer. 2014 Sep 15; 14: 672. doi: 10.1186/1471-2407-14672. PMID: 25224155

24. THOMLINSON RH, GRAY LH. The histological structure of some human lung cancers and the possible implications for radiotherapy. Br J Cancer. 1955 Dec;9(4):539-49. doi: 10.1038/bjc.1955.55. PMID: 13304213; PMCID: PMC2073776.

25. Semenza GL, Wang GL. A nuclear factor induced by hypoxia via de novo protein synthesis binds to the human erythropoietin gene enhancer at a site required for transcriptional activation. Mol Cell Biol. 1992 Dec;12(12):544754. doi: 10.1128/mcb.12.12.5447. PMID: 1448077; PMCID: PMC360482.

26. Guo $\mathrm{M}, \mathrm{Ma} X$, Feng $\mathrm{Y}$, etc al. In chronic hypoxia, glucose availability and hypoxic severity dictate the balance between HIF-1 and HIF-2 in astrocytes. FASEB J. 2019 Oct;33(10):11123-11136. doi: 10.1096/fj.201900402RR. Epub 2019 Aug 15. PMID: 31298941.

27. Louie E, Nik S, Chen JS, etc al. Identification of a stem-like cell population by exposing metastatic breast cancer cell lines to repetitive cycles of hypoxia and reoxygenation. Breast Cancer Res. 2010;12(6):R94. doi: 10.1186/bcr2773. Epub 2010 Nov 10. PMID: 21067584; PMCID: PMC3046435.

28. Zhang Q, Yan Q, Yang H, etc al. Oxygen sensing and adaptability won the 2019 Nobel Prize in Physiology or medicine. Genes Dis. 2019 Oct 19;6(4):328-332. doi: 10.1016/j.gendis.2019.10.006. PMID: 31832511; PMCID: PMC6889041.

29. Xu CY, Jiang ZN, Zhou Y, etc al. Estrogen receptor-a roles in breast cancer chemoresistance. Asian Pac J Cancer Prev. 2013;14(7):4049-52. doi: 10.7314/ apjcp. 2013. 14. 7. 4049. PMID: 23991950.

30. Jiang Z, Guo J, Shen J, etc al. The role of estrogen receptor-alpha in mediating chemoresistance in breast cancer cells. J Exp Clin Cancer Res. 2012 May 3;31(1):42. doi: 10.1186/1756-9966-31-42. PMID: 22553917; PMCID: PMC3474167

\section{Figures}


A-1

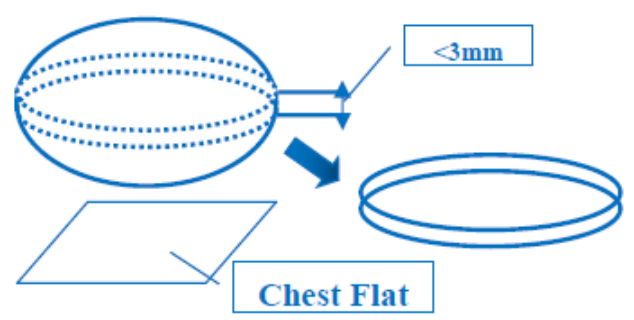

B-1

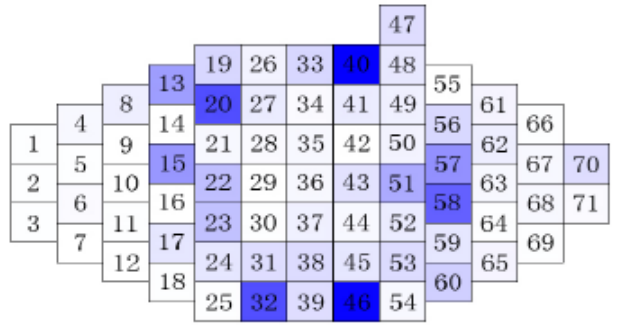

C-1

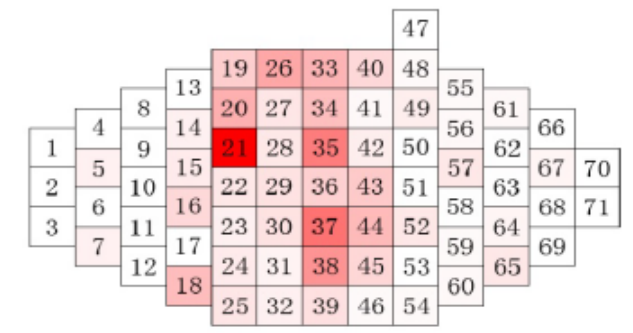

\section{C-2}

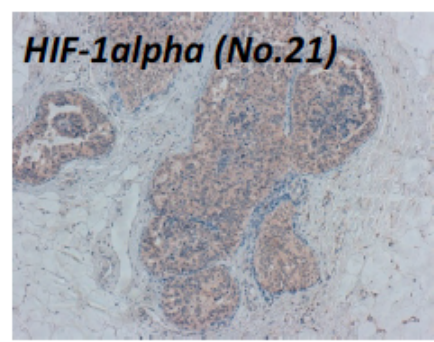

A-3

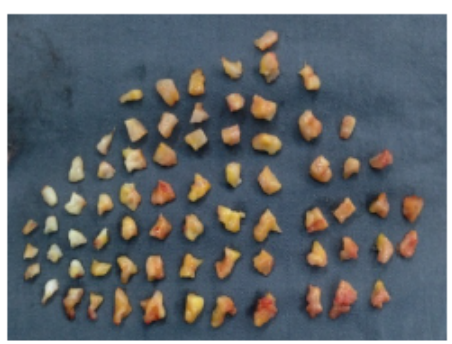

B-2

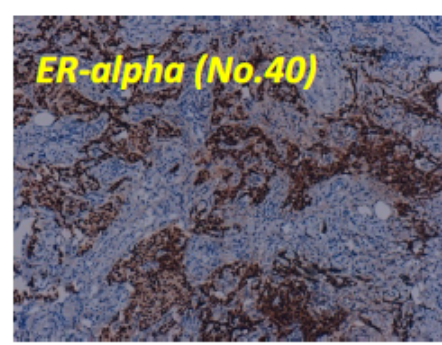

B-3

\section{ER-alpha (No.9)}

C-3

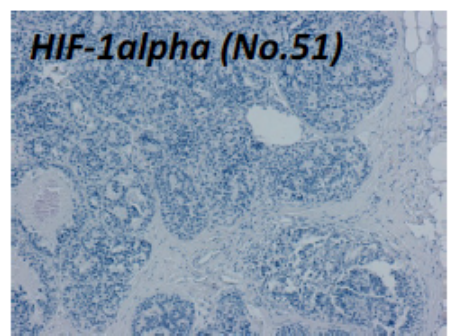

D-1

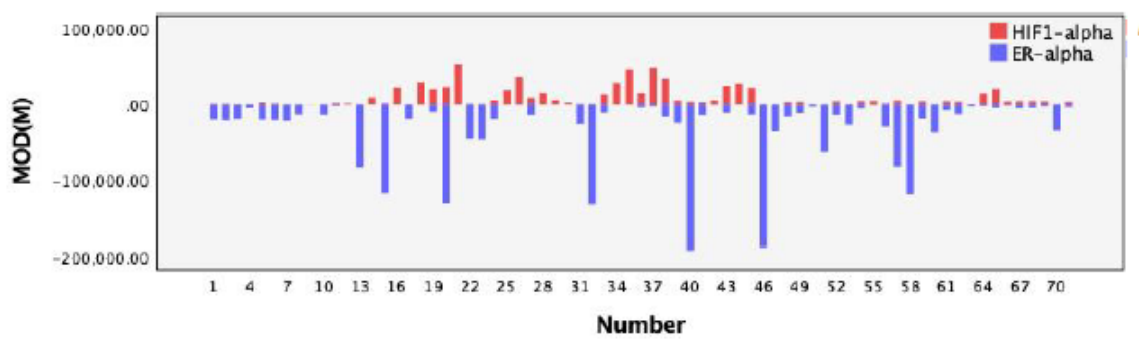

$D-2$

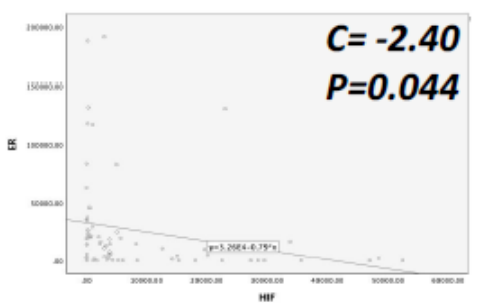

\section{Figure 1}

The Expression maps of ER-alpha and HIF-1alhpa in luminal A tumor. Tumor sample obtained from a patient with Luminal A tumor was divided into micro-blocks of less than 3mm x 3mm x 3mm, as shown in by photo A-1, 2 \& 3. Each micro-block was detected by immunohistochemistry for ER-alpha and HIF-alpha, as shown in B-1,2,3 and C-1,2,3. Mean Optical Density (MOD) values of both markers from each micro-block were analyzed according to the number order, the correlation was shown in D-1\&2.

\section{Figure 2}

Intratumoral heterogeneity and oxygen supply. The 3D reconstruction was established by the doppler ultrasound for a breast tumor which was probably malignant assessed by the ultrasound. A-1 shows that the tumor's volume was $5.1 \mathrm{ml}$ and the microvascular density (MD) was $1.5 \%$; A-2 shows that small sphere's volume was $0.53 \mathrm{ml}$ and the MD was $0.3 \%$, which was in the core of the tumor; A-3 shows that the big sphere's volume was $0.9 \mathrm{ml}$ and the MD was $1.0 \%$, which was homocentric sphere with the small sphere. The average MD of eight tumors that met the criteria is presented in $\mathrm{B}$. The tumor was diagnosed with Luminal A breast cancer and the detail pathological information postoperative is shown at the top of the $\mathrm{C}-1$. The tumor was made into large section as shown at the bottom of photo $\mathrm{C}-1$. In the large 
section the expressions of Estrogen Receptor (ER), Progestogens Receptor (PR), CD34 and Hypoxia Inducer Factor1alpha (HIF-1a) were detected immunohistochemically. Because of the large section, the tumor boundary was determined visually and established a roadmap corkscrew to the tumor center and the width of the road was more than a view under the microscopic with 100X. Each view was observed and recorded from the edge to the center and numbered from 1 to 26 . The expressions of the markers at tumor edge, medium and center for sample number 3,21 and 24 are presented in C-2 to C-13. C-14 and C-15 show correlation between expressions of ER and HIF-1alpha, and between HIF-1alpha and CD34, respectively. D-1 to D-4 show expressions (measured by Mean Optical Density) of ER, PR, CD34 and HIF -1a from eight tumors that met the criteria.

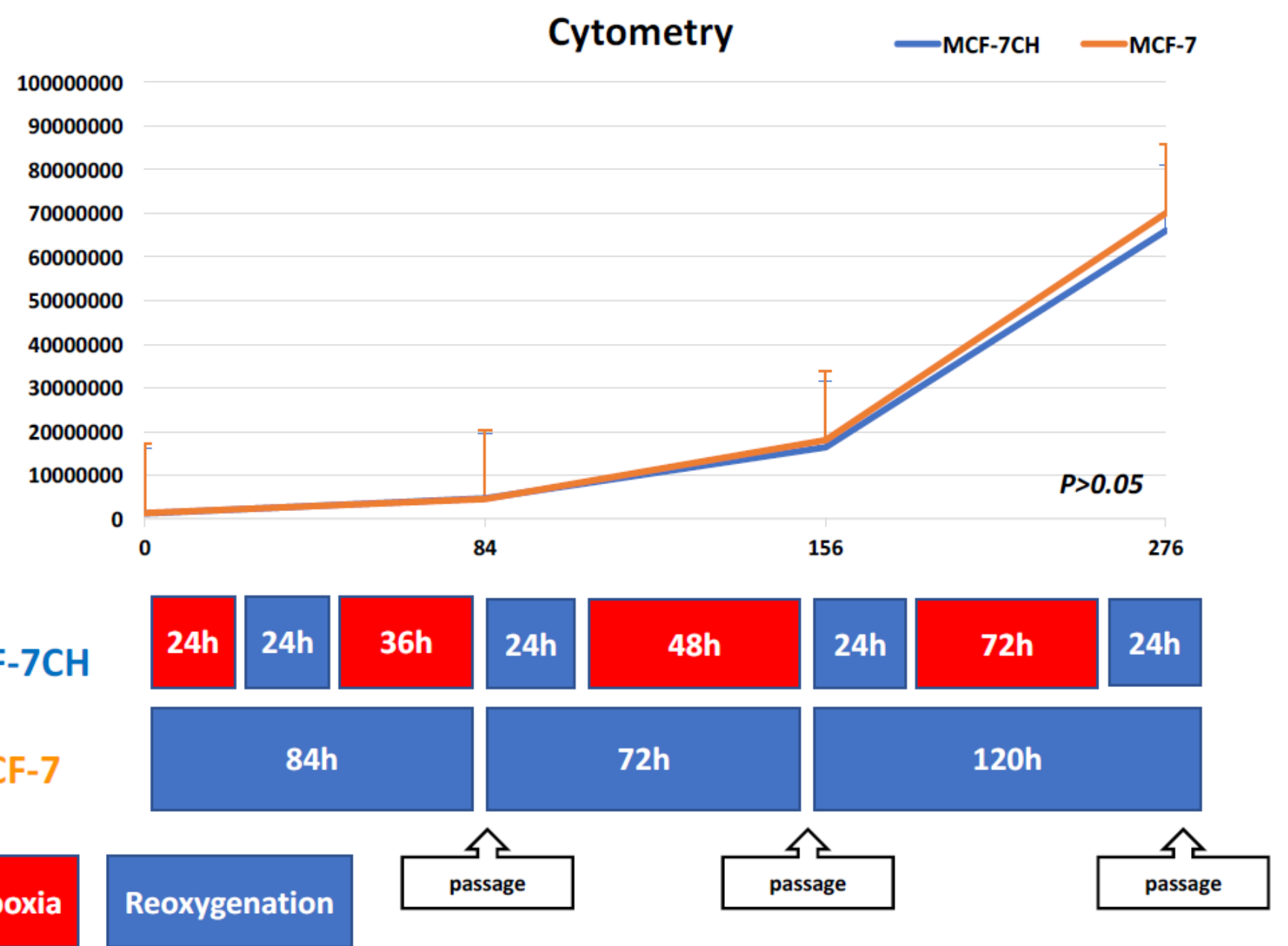

\section{Figure 3}

Ladder-type cycling hypoxia and cytometry. After 4 cycles of cycling hypoxia, the MCF-7 cells were named as MCF-7CH. Passaging cells would be carried out after hypoxia cycle in MCF-7CH group. The control group would be passaging cells at the same time point (after the beginning for 84 hours, 156 hours and 276 hours) for cytometry. The cell counting results of the two groups were shown. The red squares represent hypoxia and the blue squares represent reoxygenation. 
HIF1 $\alpha$

$\mathrm{ER} \alpha$

GAPDH control $\quad \mathrm{CH} 1 \quad \mathrm{CH} 2 \quad \mathrm{CH} 3 \quad \mathrm{CH} 4$

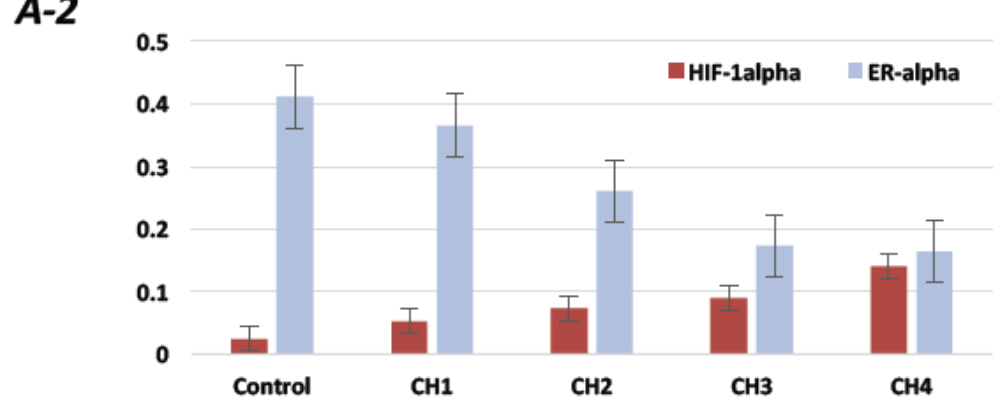

$B-1$

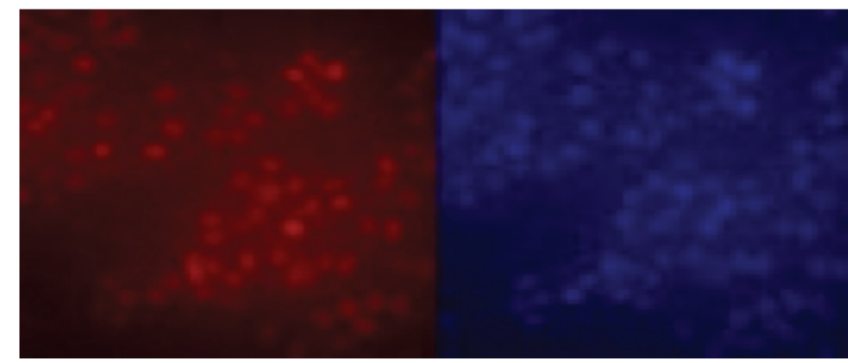

ER expression of MCF-7

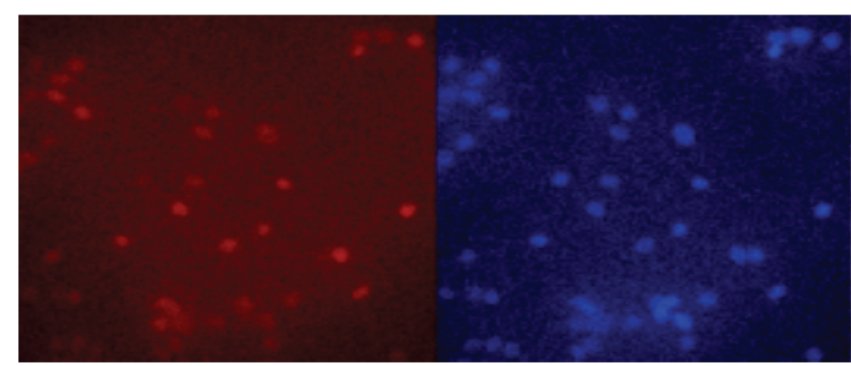

ER expression of MCF-7 after $4 \mathrm{CH}$

\section{B-2 ER-alpha}

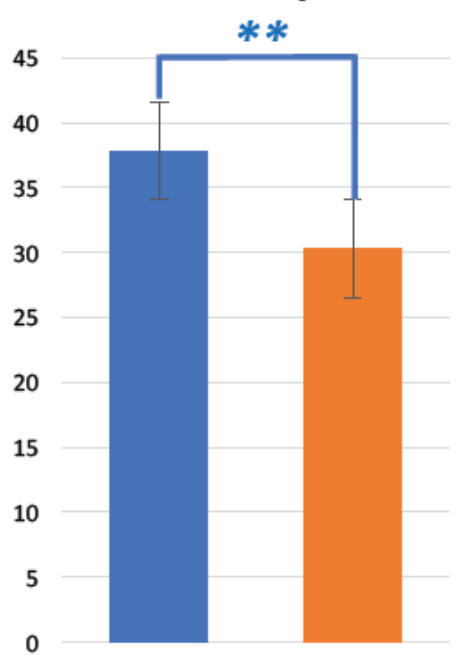

MCF-7 MCF-7CH

\section{Figure 4}

Heterogeneous sub-clones in vitro were induced by cycling hypoxia. After 4 cycles of cycling hypoxia, the MCF-7 cells were named as MCF-7CH. The expressions of HIF-1alpha and ER-alpha detected by Western Blot of each cycle of MCF7 are presented in $\mathrm{A}-1$ \& A-2. And the blots were cropped to improve the clarity and conciseness of the presentation. The expressions of ER assessed by immunofluorescence for both groups are shown in B-1 \& B-2.

\section{Supplementary Files}

This is a list of supplementary files associated with this preprint. Click to download.

- AdditionalFiles.pptx 